\title{
Outcome of the Rhomboid Flap for Recurrent Pilonidal Disease
}

\author{
Luis A. Carriquiry
}

Published online: 12 March 2009

(c) Société Internationale de Chirurgie 2009

In this issue of the World Journal of Surgery, el-Khadrawy et al. present an interesting series of recurrent pilonidal disease treated with excision and transposition of a rhomboid flap with very good results [1]. There have been recently several published studies about this technique, mainly from Turkey, where the incidence of this disease is extraordinarily high. However, these reports achieved scant echo in western surgical journals, with the exception of some British ones.

I think this technique deserves more widespread use in recurrent pilonidal disease, and I was glad to read that a recent systematic review of the disease recommends its use as a first selection in this surgical situation [2]. Of course, it is a more complex procedure, but very easily performed and does not need the collaboration of a plastic surgeon. With careful technique and hemostasis, flap transposition can be undertaken in less than half an hour and contrary to the authors' position, no drain is usually needed, as Erdem et al. [3] have shown. I usually keep my patients in the hospital for 3 or 4 days (less than the 6 days mentioned by the authors) and tell them to be careful about movements at home. I prefer to remove the skin stitches at 2 weeks. The most frequent complication-a small skin dehiscence-can be managed with local care, without the need for antibiotics. I also have been impressed by the low need for pain medication. Eliminating hair in the area continues to be of utmost importance, and the levelling of the sulcus makes shaving easier. I have used this technique in selected cases of primary pilonidal disease-in obese patients with a very deep intergluteal sulcus-with good results. Most primary cases can be treated with simpler techniques; I prefer fistulotomy, curettage, and marsupialization-reserving the rhomboid flap for recurrences.

\section{References}

1. el-Khadrawy O, Hashish M, Ismail K, Shalaby H (2009) Outcome of the rhomboid flap for recurrent pilonidal disease. World J Surg. doi:10.1007/s00268-009-9920-x

2. Lee PJ, Ranita S, Biyani DK, Watson AJM, Faragher IG, Frizelle FA (2008) Sacrococcygeal pilonidal disease. Colorectal Dis 10:639-652

3. Erdem E, Sungurtekin U, Nessar M (1998) Are postoperative drains necessary with the Limberg flap for treatment of pilonidal disease? Dis Colon Rectum 41:1427-1431
L. A. Carriquiry $(\bowtie)$

Maciel Hospital, Montevideo, Uruguay

e-mail: 1carriq@gmail.com 